\title{
HOW SCAFFOLDING CONCEPT IS REALISED THROUGH THE USE OF FEEDBACK: A SOCIOCULTURAL PERSPECTIVE
}

\author{
Entusiastik \\ Entik.entusiastik@fulbrightmail.org
}

\begin{abstract}
The aim of this paper is to discuss how the metaphor of scaffolding is realised through the use of feedback in an ESL class in the US. In doing the analysis, I look at three types of feedback (self-feedback, peer feedback, and teacher feedback) and how each type help to shape the learning process in the learning context which is discussed. A number of experimental researches indicate that L2 learners would benefit from corrective feedback regardless of the type of the feedback (Alfaajreh and Lantolf, 1994; Caroll and Swain, 1992). In the same vein, from this learning context, it can be concluded that each type of feedback can potentially serve as a mediation tool to scaffold students' learning process. Keywords: scaffolding, written feedback, self feedback, peer feedback, teacher feedback, sociocultural theory
\end{abstract}

\section{Introduction}

The language learning context analysed in this paper is an ESL Listening and Speaking class in a graduate school in the United States (US). The class consisted of eight International students from Asian and African countries majoring in International Studies. The class met each week for 90 minutes and every alternate week for another 90 minutes. In addition, a small group tutorial lasted for 45 minutes was provided for learners to consult their learning problems. The students had previously taken a placement test to 
decide their English proficiency level based on ACTFL (American Council on the Teaching of Foreign Language) and following the result these students fit in the Advanced-Mid level.

This ESL Speaking and Listening course aimed at developing students' listening and speaking skills to help them with their courses as well as prepare them to communicate effectively in their future professional work. Authentic materials taken from the online media were used as main resources for classroom activities. There was no specific textbook used as the instructional material, rather students listened to radio programmes from NPR (National Public Radio) and BBC (British Broadcasting Corporation), as well as watched TED Talks, news broadcasts from PBS (Public Broadcasting System), and other programs accessed online.

Classroom sessions generally consisted of a formal lecture, pair work, and whole class discussion. During the term, students delivered two oral presentations based on topics of their choices. Prior to delivering the oral presentations, students sent the teacher their presentation outlines and received feedback. The students would then work on the outline to create presentation slides and, for the second time, send their slides to the teacher to receive another feedback. The presentations were video recorded, and this was done for assessment purposes. Besides giving feedback for the students, the teacher asked the students to watch their own presentations and comment on the presentations. During the oral presentation in class, the students were also asked to give feedback for their classmates. Hence, the students would receive three forms of feedback -from themselves (self-feedback), from their classmates (peer feedback), and from the teacher (teacher feedback). 
As feedback appeared to take a considerable part in shaping the language learning process as well as in teacher-student interaction in this learning context, I would like to explore this further in relation to the sociocultural theory. In my presentation, I begin with the theoretical framework to position feedback from sociocultural perspectives, then I discuss each form of feedbacks used in the learning context specified above and how feedback is potential to scaffold learning process.

\section{Literature Review}

\section{a. Roles of Teacher and Student in language learning from Sociocultural perspective}

The constructivist learning theory brings a new perspective in perceiving a learner as an individual who actively constructs knowledge (Pritchard, 2013). Vygotsky hypothesised that learning is a socially and culturally constructed process rather than individually determined phenomena (Kozulin et.al., 2003). Within this concept, learners are more than just an individual with physical and mental characters, rather they are socially and culturally situated. Whereas teacher's role is not merely as a source of knowledge, rather they mediate the learning process. From the learning context described in this paper, teacher-student interaction and student-student interaction were evidenced particularly when the teacher provided feedback before and after the presentations, as well as in the assessment procedure in which students were involved actively in evaluating self and peer's performances.

\section{b. Mediation in learning: Scaffolding}

Grounded in Vygotsky's theory in the concept of learning as a social and cultural activity, during the learning process 'psychological tools' (e.g. language, mnemonic 
techniques, writing, diagrams, maps) are associated and used to mediate knowledge construction (Lantolf and Appel, 1994; Wertsch, 2007). Wertsch (2007, p. 180) touches on two types of mediation: 'explicit mediation' which refers to human and stimulus means mediation, and 'implicit mediation' which refers to social and inner speech mediation. The notion of mediation may also refer to human mediation and mediation in the form of organized learning activity (Kozulin, 2003). In the classroom context, mediation is a common concept assuming the distance in terms of linguistic and conceptual knowledge between teachers and students (Gibbons, 2003). One prominent mediational concept is scaffolding, and this will be the main theme of analysis within this paper.

Referring to the work of Wood, Bruner, and Ross (1976), scaffolding was defined as the assistance provided by an expert in order for a novice to complete a task or solve a problem, assuming a teacher role as the scaffolder. However, there are at least three criticisms with this definition concerning the focus on the expert's role, inadequate explanation of the process, and the failure to take the novice's creativity into account (Granott, 2005; Mascolo, 2005). The notion of scaffolding, therefore, has evolved beyond the central role of the expert as support provider as interaction among learners could also provide similar support for each other (De Guerrero and Villamil, 2000; Donato, 1998; Granott, 2005; Ohta, 1995). The fact that an individual can scaffold themselves is also discussed by Bickhart (2005) and Granott (2005) hence, the traditional concept of scaffolding has broadened its perspective.

Next, I specify the form of scaffolding which serves as the centre of discussion. Tharp and Gallimore (1988) define feedback as one of the main scaffolding mechanism in assisted performance context. Classroom context-based researches describe teacher's 
guidance to help learners complete a task using linguistics 'scaffolding tools' such as question, feedback, and task structure description (Maybin, Mercer, and Stierer, 1992; Mercer 1995; cited in Fernandez et.al., 2015, p. 54). Similarly, Schaffer (1996, cited in Kozulin, 2003), notes several forms of scaffolding provided by teacher including the role in creating a secure learning environment, support, challenge, and feedback. Feedback is also mentioned by Wells (1999, p.141) when discussing 'semiotic apprenticeship' to characterise learning in school context: 'They should also receive assistance in their learning in the form of appropriate models and constructive feedback and guidance.'

While scaffolding can be explained from three different perspectives, how I define feedback will be based on various ethnographic research data observed by Alfaajreh and Lantolf (1994, p.465) in which a feedback 'may be self- or other-initiated and self- or other-completed ... in the form of provision of the correct form by teacher, peer, or native interlocutor'. Having specified this, and following types of scaffolding from the three perspectives mentioned earlier. Hence, the paper is looking at how self-feedback, peer feedback, and teacher feedback can support language learning in the context of the ESL Speaking and Listening class described above.

\section{Method}

This library-based research serves as a critical review on the notion of scaffolding by looking at the use of three different types written feedback used in an ESL class in the US. Data were gathered from records obtained by one of the former students in the class in forms of self-feedback, peer feedback, and teacher feedback. These feedbacks mediated learning, therefore considered as a scaffolding, and were given prior to and following an individual presentation lasting for 5-7 minutes. Analysis on the feedback was carried out 
based on the current perspectives and theories of scaffolding in which the learners himself and his peers may serve as the support providers.

\section{Results and Discussions}

a. Sociocultural Perspectives on Teacher Feedback as scaffolding

In the learning context discussed, the teacher feedbacks were provided before and after the main task (oral presentations). The pre-task feedback was first given to inform the students about the topic they chose to present. The second pre-task feedback was given in response to the presentation slides prepared by the students. The third feedback covered mainly three areas of students' oral presentation: presentation content, presentation organization, and language use and will be mainly discussed and referred in this paper. Figure 1 below illustrates the first part of the teacher feedback for the oral presentation.

Task: Deliver a 5-7 min $\lrcorner$ te presentation about a topic of your choice, with the objective of engaging the aucience to inform them about your topic. Use of PowerPcint requ rec.

Introduction and Overview - good introduction and engagement

Eye Contact - very good. The topic was a more personal theme sc it lent itselt to being more informal, but in future, because aware that having your hands in your oockets can be a b t too informal for a presentation.

Engaged the Audience - you had a lct of engagement with questions for the audience (gocd) but sometimes you cidn't $g$ ve them a chance to answer the quest ons

Organization - the organization was gocd. Ycu followed ycur points from the outline and the progression was clear.

Power Point-generally effective. Not too much text, and pictures added to the delivery. Nice

Condusion - The conclusion was good in that vou stated that vcu might be wrong because the presentation was about your conclusions about American culture. However, it seemed a little flat with the simple thank you.

Fig. 1 Teacher Feedback part 1 (presentation delivery) 
Through the lense of sociocultural perspective, corrective feedback serves to help learners to move from other regulation in the Zone of Proximal Development (ZPD) to self-regulation (Ellis, 2012). Apart from the long going debate around the use of feedback, a number experimental researches indicate that L2 learners perform better than the control group which does not receive feedback (Alfaajreh and Lantolf, 1994). A study by Caroll and Swain (1992) suggest that both implicit and explicit feedback will support learning, while at the same time highlight a more significant effect of the explicit feedback. In another study, Carroll, Roberge and Swain (1993) reported that especially advanced learners would benefit from correction which inFvolves both positive input and negative feedback due to their more developed capacity in language processing and language retention.

Drawing on Vygotsky's notion of ZPD, Alfaajreh and Lantolf (1994) study how error correction lead to learning during teacher and students interaction. They argued that feedback will promote learning provided the correction is relevant to learner's ZPD and the process involves negotiation between the learner and the expert. In this learning context, as the teacher has guided the students to prepare for the oral presentation through several stages (from topic selection to presentation slides preparation), it is argued that the students worked in their ZPD. During the first two pre-task feedbacks (for outline and slides) there appeared to be negotiation between the teacher and students regarding the standard set by the teacher and the goals set by the students.

Looking at the feedback in Figure 1, most comments made by the teacher indicated both positive and negative feedback along with a short explanation. The positive feedback is indicated by words like 'good, nice and effective' when referring to any achievements made by the student during the presentation. While the negative feedback is indicated by 
the word 'but' in such clauses as '... but ... aware that having your hands in your pocket can be a bit too informal ...' and 'but sometimes you didn't give them a chance to answer the questions.' Also, the teacher seemed to lessen the effect of the negative feedback by commenting on the good side first.

The next part of the teacher's feedback addressed errors in linguistic forms including grammar, lexis, and pronunciation. Following Alfaajreh and Lantolf (1994), teacher's corrective feedback can be message- or code-focused, and particularly in a classroom setting, they suggest that more attention should be given to error in meaning than in form (grammar, vocabulary, or pronunciation). In this learning context, the teacher provided feedback on the student's language use (code) after commenting on the content of the presentation (message). However, looking at the details of the items corrected, it is hard to conclude whether the teacher meant to put more attention on content rather than on language aspect.

Carroll and Swain (1993) state that providing the correct forms without further grammatical or lexical explanation might be less helpful. In this context, the teacher provided feedback for language use explicitly by showing and correcting the errors. The teacher might assume that simply by correcting the errors, these advanced learners would understand and learn from their mistakes. 
Specific grammar/lexis/pronunciation:

Lexis:

Share you my experiences $\rightarrow$ share my experiences with you

On the trash $\rightarrow$ in the trash

I will feel a bit difficult $\rightarrow$ it will feel difficult to me

That's the euphoria thing $\rightarrow$ euphoria stage

I will lost like thousands time $\rightarrow$ ? ?

Food is big issue for me $\rightarrow$ a big issue

My stomach will screaming $\rightarrow$ will scream (MODALS!!)

Taking classes for audit basis $\rightarrow$ on an audit basis

What I means $\rightarrow$ what I mean

Making friendships $\rightarrow$ forming friendships or making friends

Grammar:

What can characterizes $\rightarrow$ can characterize

It means you don't have meal yet $\rightarrow$ it means you haven't had a meal yet

So positive people $\rightarrow$ such positive people

Presentation skills: A-

Content skills: B+

Final score: $A$ -

Figure 2: Teacher Feedback part 2 (language use)

b. Sociocultural Perspectives on Peer Feedback as Scaffolding

During the oral presentation, non-presenting students were asked to observe and write feedback for the presenter. In doing this, the teacher has specific instruction regarding the area to focus on by providing guiding questions: 1) What was good from the presentation?, 2) What could be improved from the presentation? and 3) What did you learn from the presentation?. I personally think that this activity encourages students to engage in their peers' presentation as they did not only listen to it but also showed evidence of their attending.

Foster and Ohta $(2005, \mathrm{p} .426)$ state that 'interactional processes including negotiation for meaning and various kinds of peer assistance and repair are among the many ways learners gain access to the language being learned.' This is supported by many other studies which indicate that scaffolding occurred during peer interactions in the process of 
knowledge co-construction (e.g. De Guerrero and Villamil, 2000; Donato, 1998; Granott, 2005; Ohta, 1995;). Specific to peer-feedback, Sato (2013) investigates learners' perception on peer corrective feedback and how these students see their peers as learning resources. This study finds that learners show positive attitudes towards peer corrective feedback especially after given training on peer interaction and on how to provide corrective feedback.

In assessing the effectiveness of peer feedback, it is also important to consider factors which influence quantity and quality of peer feedback. Allen and Katayama (2016) find that among those several factors (e.g. social and cultural background) learners' language proficiency together with their perception of their own and their peers' proficiency play a significant role in creating successful feedback activity. They also find that learners who know each other well will feel more comfortable during this activity, thus, resulting in a more natural comment in their feedback.

The peer feedback illustrated in this context was produced by graduate students with Advanced English proficiency. Though the level of relationship among students in this class cannot be stated, looking at the small size of the class ( 8 students), similar background (all international students), and classroom meeting frequency (7-8 times@90 minutes per month), it is safe to say that they all know each other quite well. Given the facts, the context is supportive for peer feedback activity. Looking at the peer feedback itself, many comments were written clearly showing students' willingness to provide a meaningful message, and indicated that peer feedback in this context might serve as a resource which can help students gain more perspective on his/her performance. 


\section{Comments from peers- Good points}

personal experience in the US

her motions of her hands looked yery natural

speaker's impression was cardidly irt-oduced, and I had comsassion good example for demonstrating cultural shuck

she was very contident

compassionate, interesting stcries outllre, organization

\section{What could have been better What thay learned}

cultural differences batween Indonesia and the US, her ouvn experiences and feeling

gond to know other internaticnal students culture st ock feeling

her emotions after arriving in the us

cultural differences

se ective in demonstrating some cultural sliock

It'd have been better if she

When a presenter talks about a topic he/she knows very well, it sounds more persuasive

\section{of time}

ppt can be better, a little bit nervous culture shock curve

her personal experlence

Figure 3: Peer Feedback

c. Sociocultural Perspectives on Self Feedback

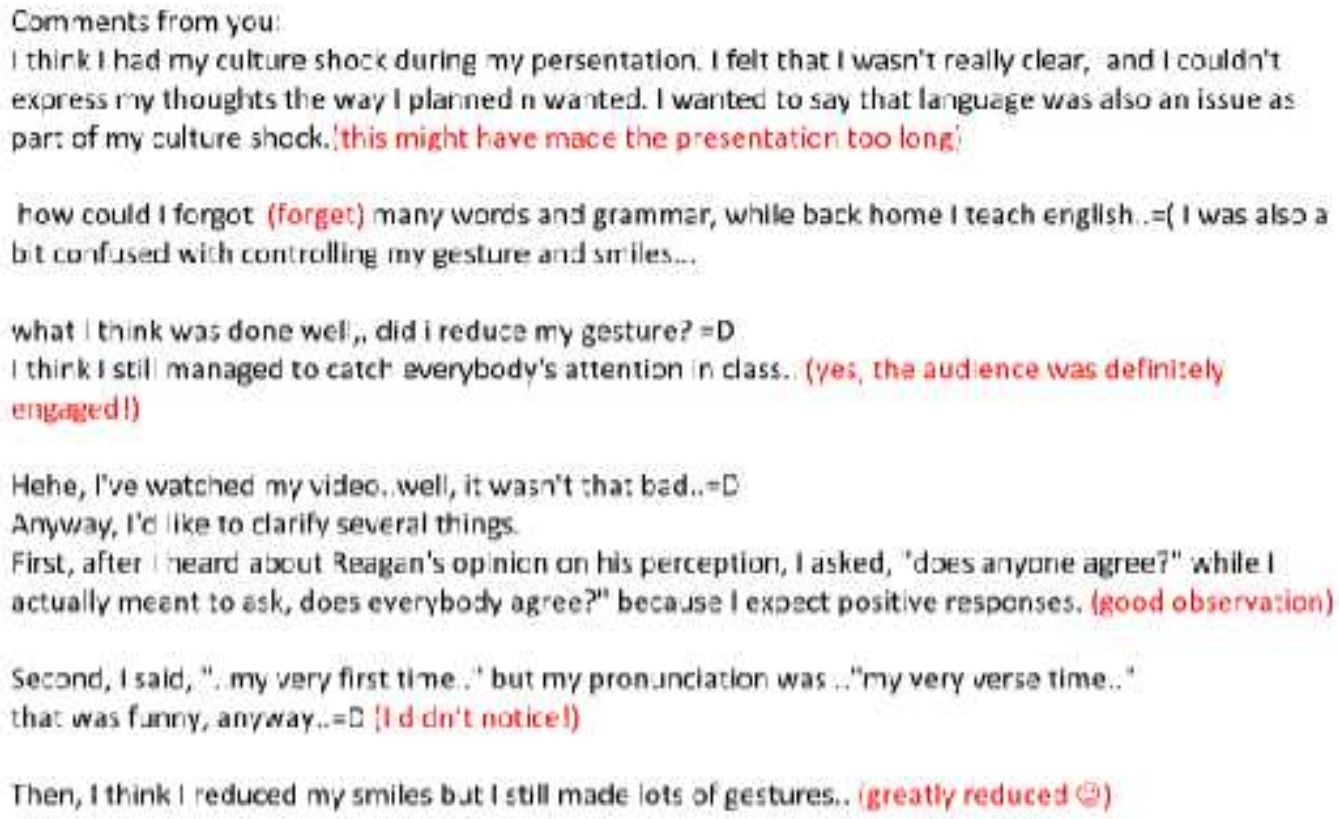

Figure 4: Self-feedback 
Swain et. al. (2009) argue that languaging or self-explaining helps learners understand language concept better. One type of languaging that they found influential for learners' performance is self-assessment in which students monitor their understanding. In the next study Swain et. al. (2010) find that languaging is a self-scaffolding tool to explore new meaning and to understand the teaching material. The role of self-assessment as a mediation tool was also investigated by Donato and MacCormick (1994) through the use of portfolio to document and reflect students' language development.

The self-feedback illustrated above was a description of self-assessment done by a student after watching her own presentation. The student reflected on what she thought was good and what she could've improved while also explaining what she felt during the presentation. The student also appeared to spot some grammatical and pronunciation errors made during the presentation. This self-repair, according to Van Lier (1988, cited in Alfaajreh and Lantolf, 1994) is an important learning activity. Another interesting fact is that the teacher showed her response immediately after each comment which made the self-feedback appeared to serve as a dialogic tool that helps the student construct knowledge.

\section{Conclusion}

The feedback provided by teacher, peer, or self in this learning context appear to potentially serve as a mediation tool in learning process. The strategy applied by the teacher to engage students through feedback activity extended the opportunity for students to learn from their selves and their peers and enhanced the learning experience. The use of peer feedback and self-feedback were effective in raising students' awareness to monitor their own progress in learning. However, more attention should be given to the content of 
the teacher feedback including which area to focus depending on the students' needs and learning goals and how much explanation to include.

\section{About the writer}

Entusiastik finished her undergraduate study at the University of Airlangga, Surabaya from the Faculty of Humanities, English Department. She then taught at several different language schools including International Language Program (ILP) Surabaya, and the Language Center of University of Airlangga. She has recently obtained a Master's degree in TESOL (the Teaching of English for Speakers of Other Languages) from the Institute of Education, University College London, UK and currently serves as a lecturer at Kadiri Islamic University (UNISKA) and State Islamic Institute of Kediri.

\section{References}

Aljaafreh, A. and Lantolf, J.P. (1994). Negative feedback as regulation and second language learning in the zone of proximal development. The Modern Language Journal, 78(4), pp.465-483.

Allen, D. and Katayama, A. (2016). Relative second language proficiency and the giving and receiving of written peer feedback. System, 56, pp.96-106.

Bickhard, M.H. (2005). Functional scaffolding and self-scaffolding. New Ideas in Psychology, 23(3), pp.166-173. 
Carroll, S., Swain, M. and Roberge, Y. (1992). The role of feedback in adult second language acquisition: Error correction and morphological generalizations. Applied Psycholinguistics, 13(2), pp.173-198.

Caroll, S. and Swain, M. (1993). Explicit and implicit negative feedback: An empirical study of the learning of linguistic generalization. Studies in Second Language Acquisition, 15, pp.357-386.

De Guerrero, M. and Villamil, O.S..(2000). Activating the ZPD: Mutual scaffolding in L2 peer revision. The Modern Language Journal, 84(1), pp.51-68.

Donato, R. (1998). Collective scaffolding in second language learning. In Lantolf, J.P and Appel, G. (Eds). Vygotskian approaches to second language research. New Jersey: Ablex Publishing Company. Ch 2.

Donato, R. and McCormick, D., (1994). A sociocultural perspective on language learning strategies: The role of mediation. The Modern Language Journal, 78(4), pp.453-464.

Ellis, R (2012). Language teaching research and language pedagogy. West Sussex: John Wiley \& Sons.

Fernández, M., Wegerif, R., Mercer, N. and Rojas-Drummond, S. (2015). Reconceptualizing" scaffolding" and the zone of proximal development in the context of symmetrical collaborative learning. The Journal of Classroom Interaction, pp.54-72.

Foster, P. and Ohta, A.S.(2005). Negotiation for meaning and peer assistance in second language classrooms. Applied Linguistics, 26(3), pp.402-430. 
Gibbons, P. (2003). Mediating language learning: Teacher interactions with ESL students in a content based classroom. Tesol Quarterly, 37(2), pp.247-273.

Granott, N. (2005). Scaffolding dynamically toward change: Previous and new perspectives. New Ideas in Psychology, 23(3), pp.140-151

Kozulin, A. (2003). Psychological tools and mediated learning. In Kozulin, A., Gindis, B., Ageyev, V.S. and Miller, S.M., Vygotsky's educational theory in cultural context. 2003. pp.15-38.

Kozulin, A., Gindis, B., Ageyev, V.S. and Miller, S.M. (2003). Introduction: Sociocultural theory and education: Students, teachers, and knowledge. Vygotsky's educational theory in cultural context, pp.1-14.

Lantolf, J.P. and Appel, G. (1994). Vygotskian approaches to second language research. London: Greenwood Publishing Group.

Mascolo, M.F. (2005). Change processes in development: The concept of coactive scaffolding. New Ideas in Psychology, 23(3), pp.185-196.

Ohta, A.S. (1995). Applying Sociocultural Theory to an Analysis of Learner Discourse: Learner-Learner Collaborative Interaction in the Zone of Proximal Development. Issues in Applied linguistics, 6(2), pp.93-121.

Pritchard, A. (2013). Ways of learning: Learning theories and learning styles in the classroom. London: Routledge.

Sato, M. (2013). Beliefs about peer interaction and peer corrective feedback: Efficacy of classroom intervention. The Modern Language Journal, 97(3), pp.611-633. 
Swain, M., Lapkin, I. Knouzi, W. Suzuki, and Brooks L. (2009) Languaging: university students learn the grammatical concept of voice in French. Modern Language Journal 93: $6-30$

Knouzi, I., Swain, M., Lapkin, S. and Brooks, L. (2010). Self scaffolding mediated by languaging: microgenetic analysis of high and low performers. International Journal of Applied Linguistics, 20(1), pp.23-49.

Tharp, R.G. and Gallimore, R. (1988). Rousing minds to life. Teaching and learning in social contexts. Cambridge: Cambridge University Press.

Wells, G. (1999). Dialogic inquiry: Towards a socio-cultural practice and theory of education. MA: Cambridge University Press.

Wertsch, J.V. (2007). Mediation. In Daniels, H. Cole, M. and Wertsch, J.V. (Eds). The Cambridge Companion to Vygotsky. Cambridge: Cambridge University Press. Ch. 7.

Wood, D., Bruner, J.S. and Ross, G. (1976). The role of tutoring in problem solving. Journal of child psychology and psychiatry, 17(2), pp.89-100. 


\section{Appendix: The full form of the Feedback (copied from the original document)}

\section{1/19/10 Presentation}

Task: Deliver a 5-7 minute presentation about a topic of your choice, with the objective of engaging the audience to inform them about your topic. Use of PowerPoint required.

Introduction and Overview - good introduction and engagement

Eye Contact - very good. The topic was a more personal theme so it lent itself to being more informal, but in future, because aware that having your hands in your pockets can be a bit too informal for a presentation.

Engaged the Audience - you had a lot of engagement with questions for the audience (good) but sometimes you didn't give them a chance to answer the questions

Organization - the organization was good. You followed your points from the outline and the progression was clear.

Power Point-generally effective. Not too much text, and pictures added to the delivery. Nice.

Conclusion - The conclusion was good in that you stated that you might be wrong because the presentation was about your conclusions about American culture. However, it seemed a little flat with the simple thank you.

\section{Comments from peers-}

Good points

good pace and deep reflection

personal experience in the US

her motions of her hands looked

very natural

speaker's impression was

candidly introduced, and I had

compassion

good example for

demonstrating cultural shock

she was very confident

compassionate, interesting

stories

outline, organization

\section{What could have been better What they learned} cultural differences between Indonesia and the US, her own experiences and feeling good to know other international students

PPT

more structured contents culture shock feeling her emotions after arriving in the US

cultural differences

not much

selective in demonstrating some cultural shock

It'd have been better if she was able to lessen the amount of time ppt can be better, a little bit nervous
When a presenter talks about a topic he/she knows very well, it sounds more persuasive

culture shock curve her personal experience 
Comments from you:

I think I had my culture shock during my persentation. I felt that I wasn't really clear, and I couldn't express my thoughts the way I planned $\mathrm{n}$ wanted. I wanted to say that language was also an issue as part of my culture shock.(this might have made the presentation too long)

how could I forgot (forget) many words and grammar, while back home I teach english..=( I was also a bit confused with controlling my gesture and smiles...

what I think was done well, did i reduce my gesture? =D

I think I still managed to catch everybody's attention in class.. (yes, the audience was definitely engaged!)

Hehe, I've watched my video..well, it wasn't that bad..=D

Anyway, I'd like to clarify several things.

First, after I heard about Reagan's opinion on his perception, I asked, "does anyone agree?" while I actually meant to ask, does everybody agree?" because I expect positive responses. (good observation)

Second, I said, "..my very first time.." but my pronunciation was .."my very verse time.." that was funny, anyway..=D (I didn't notice!)

Then, I think I reduced my smiles but I still made lots of gestures.. (greatly reduced (:))

\section{Specific grammar/lexis/pronunciation:}

Lexis:

Share you my experiences $\rightarrow$ share my experiences with you

On the trash $\rightarrow$ in the trash

I will feel a bit difficult $\rightarrow$ it will feel difficult to me

That's the euphoria thing $\rightarrow$ euphoria stage

I will lost like thousands time $\rightarrow$ ??

Food is big issue for me $\rightarrow$ a big issue

My stomach will screaming $\rightarrow$ will scream (MODALS!!)

Taking classes for audit basis $\rightarrow$ on an audit basis

What I means $\rightarrow$ what I mean

Making friendships $\rightarrow$ forming friendships or making friends

Grammar:

What can characterizes $\rightarrow$ can characterize

It means you don't have meal yet $\rightarrow$ it means you haven't had a meal yet

So positive people $\rightarrow$ such positive people

Presentation skills: A-

\section{Content skills: B+}

Final score: A- 


\section{Appendix 2: Email Screenshots}

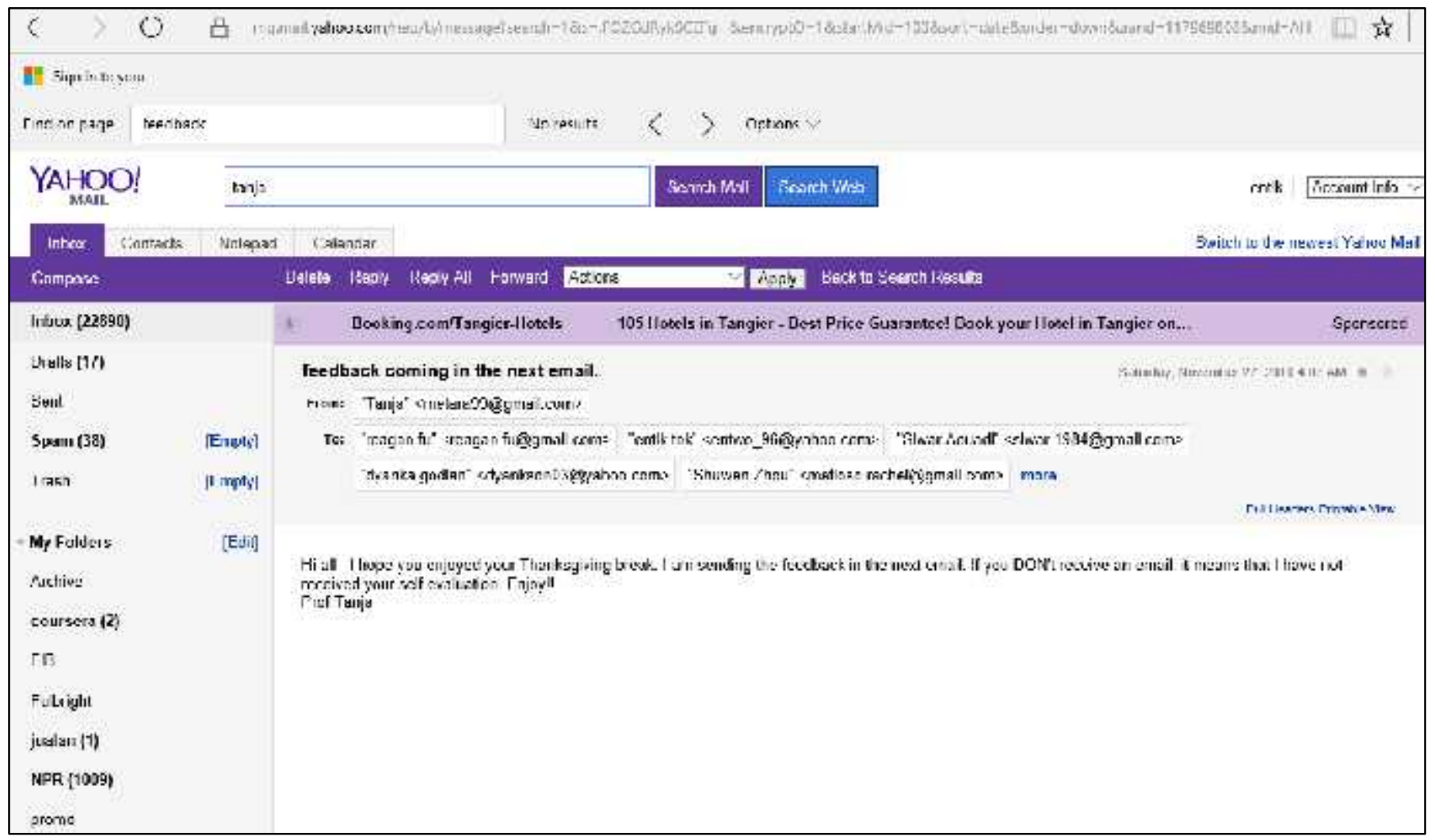

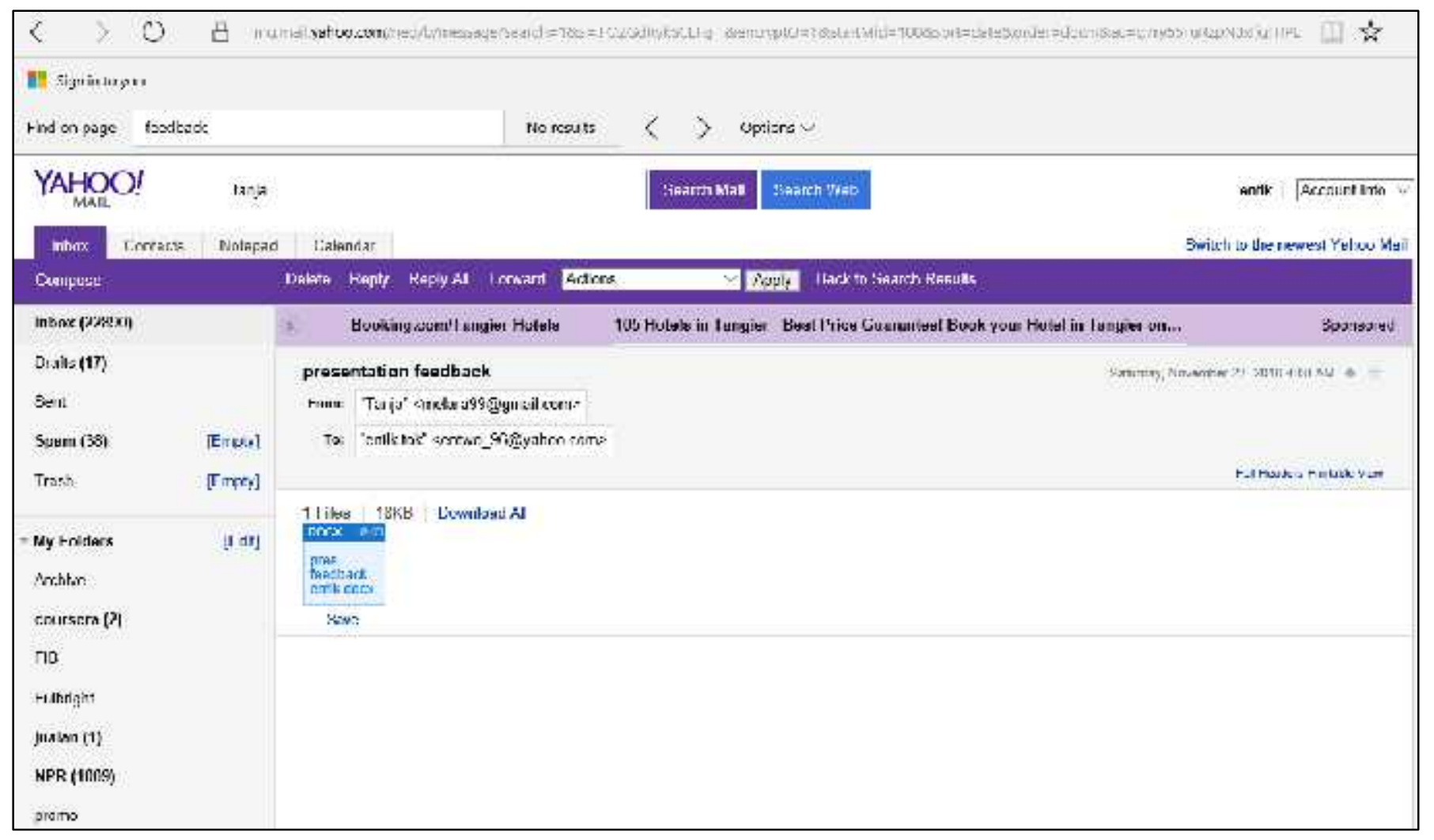

